\title{
Update on optimal use of omalizumab in management of asthma
}

This article was published in the following Dove Press journal:

Journal of Asthma and Allergy

10 June 2011

Number of times this article has been viewed

\section{Girolamo Pelaia' \\ Luca Gallelli' \\ Teresa Renda' \\ Pasquale Romeo' \\ Maria Teresa Busceti' \\ Rosa Daniela Grembiale \\ Rosario Maselli' \\ Serafino Antonio Marsico ${ }^{2}$ \\ Alessandro Vatrella ${ }^{3}$ \\ 'Department of Experimental and \\ Clinical Medicine, University Magna \\ Græcia of Catanzaro, Catanzaro; \\ ${ }^{2}$ Department of Cardiothoracic and Respiratory Sciences, Second \\ University of Naples, Naples; \\ ${ }^{3}$ Department of Respiratory Medicine, University of Salerno, Salerno, Italy}

Correspondence: Girolamo Pelaia Campus Universitario S Venuta, Viale Europa, Località Germaneto, 88100 Catanzaro, Italy

$\mathrm{Tel}+39096$ I364 7302

Fax + 39096 I364 7193

Email pelaia@unicz.it

\begin{abstract}
Omalizumab is a humanized monoclonal anti-IgE antibody recently approved for the treatment of severe allergic asthma. This drug inhibits allergic responses by binding to serum IgE, thus preventing interaction with cellular IgE receptors. Omalizumab is also capable of downregulating the expression of high affinity $\operatorname{IgE}$ receptors on inflammatory cells, as well as the numbers of eosinophils in both blood and induced sputum. The clinical effects of omalizumab include improvements in respiratory symptoms and quality of life, paralleled by a reduction of asthma exacerbations, emergency room visits, and use of systemic corticosteroids and rescue bronchodilators. Omalizumab is relatively well-tolerated, and only rarely induces anaphylactic reactions. Therefore, this drug represents a valid option as add-on therapy for patients with severe persistent allergic asthma inadequately controlled by high doses of standard inhaled treatments.
\end{abstract}

Keywords: omalizumab, anti-IgE, severe asthma

\section{Introduction}

Asthma is a complex and heterogenous disease characterized by various immunopathologic and clinical phenotypes, based on different patterns of airway inflammation involving immune/inflammatory cell types, such as T and B lymphocytes, mast cells, eosinophils, basophils, neutrophils, monocytes/macrophages, and dendritic cells, as well as structural cellular elements, including both epithelial and mesenchymal cells., ${ }^{1,2}$ This widespread respiratory disease, which originates from multiple interactions between genetic factors and environmental agents, such as allergens, respiratory viruses, and airborne pollutants, is characterized by recurrent episodes of dyspnea, wheezing, chest tightness, and cough, usually associated with reversible airflow limitation and an exaggerated bronchoconstrictive response to several different stimuli (airway hyper-responsiveness). Asthma constitutes a heavy medical, social, and economic burden, and its prevalence is steadily increasing worldwide. ${ }^{3}$ Indeed, asthma affects over 300 million people around the world, and some epidemiologic projections estimate that this number will increase further during the next few decades. ${ }^{4}$ Although good control of asthma symptoms can be achieved in a large proportion of patients by current standard therapies, mainly based on combinations of inhaled corticosteroids and $\beta_{2}$-adrenoceptor agonists, ${ }^{5,6}$ a small percentage (about $5 \%-10 \%$ ) of asthmatic subjects who are affected by the most severe forms of the disease, although receiving the best available inhaled treatments, remain symptomatic and inadequately controlled, thus having a poor quality of life. In these patients, asthma symptoms can be further 
worsened by concomitant comorbidities, including rhinitis, sinusitis, gastroesophageal reflux, obesity, and obstructive sleep apnea. ${ }^{7}$ Patients with uncontrolled asthma have a high risk of serious morbidity and mortality, thereby representing the most severe sector of the overall phenotypic asthma spectrum, characterized by the greatest unmet medical needs. ${ }^{8}$ Therefore, although being a minority of the global asthmatic population, patients with severe asthma are those who use the largest share of economic resources and health care services, including emergency visits, hospitalizations, and additional consumption of drugs utilized for recurrent exacerbations. A further social and economic impact of difficult-to-treat asthma arises from the frequent loss of school and work days due to such a disabling condition. Moreover, patients with severe asthma often show a tendency to anxiety and depression, which can further impair disease control by reducing their compliance with prescribed medications.

IgE antibodies are crucially involved in mediating, maintaining, and amplifying the allergic cascade. ${ }^{9}$ Similar to the other antibody classes, the IgE structure consists of two variable antigen-binding fragments and a receptorbinding constant portion ( $\mathrm{Fc})$. In particular, the IgE molecule (molecular weight $190 \mathrm{kD}$ ) comprises two identical light chains, each made of a variable $\left(\mathrm{V}_{\mathrm{L}}\right)$ and a constant domain $\left(\mathrm{C}_{\mathrm{L}}\right)$, as well as two identical heavy chains, each including a single-domain variable region $\left(\mathrm{V}_{\mathrm{H}}\right)$ and a constant region containing four domains ( $\mathrm{C} \varepsilon 1, \mathrm{C} \varepsilon 2, \mathrm{C} \varepsilon 3, \mathrm{C} \varepsilon 4)$. IgE binds to its high affinity FceRI receptor, expressed as an $\alpha \beta \gamma_{2}$ tetramer on mast cells and basophils, and as an $\alpha \gamma_{2}$ trimer on human antigen-presenting cells, monocytes, eosinophils, platelets, and smooth muscle cells. ${ }^{10}$ The IgE-binding function of FceRI is located within the two extracellular domains of its $\alpha$ chain, which interact with the two CE3 domains of $\mathrm{IgE}$, whereas the intracellular $\beta$-chains and $\gamma$-chains are involved in signal transduction. At the level of the mast cell surface, adjacent allergenic epitopes induce the aggregation of two or more FceRI-bound IgE molecules (cross-linking), thus triggering mast cell degranulation.

It is well-known that the propensity to develop exaggerated IgE responses to common environmental allergens, referred to as atopy, plays a dominant role in the pathologic features and clinical manifestations of allergic asthma. Therefore, given the key importance of IgE in the immunoinflammatory mechanisms underlying atopic asthma, such a condition can greatly benefit from IgE-targeted therapies. ${ }^{10-14}$ In particular, according to various studies IgE-mediated positive reactions to skin prick tests for common aeroallergens are detectable in a percentage of severe asthmatics, ranging from about $50 \%-80 \%{ }^{8,15,16}$

For all these reasons, anti-IgE therapy was included in 2006 within step 5 of the Global Initiative for Asthma guidelines ${ }^{17}$ as add-on treatment to inhaled and eventually oral corticosteroids, long-acting $\beta_{2}$-agonists, and other controller medications, such as leukotriene-modifiers and theophylline. After being introduced in Australia in 2002 and US in 2003, utilization of omalizumab, an anti-IgE monoclonal antibody, was also approved in 2005 by the European Medicines Agency as add-on therapy to improve asthma control in adult and adolescent patients (12 years of age and above) with severe persistent allergic asthma, who have an impaired lung function (forced expiratory volume in 1 second $\left[\mathrm{FEV}_{1}\right]<80 \%$ predicted) and experience frequent daytime symptoms and/or nocturnal awakenings, associated with multiple severe exacerbations despite daily high doses of inhaled corticosteroids and long-acting $\beta_{2}$-adrenoceptor agonists. More recently, the use of omalizumab has also been approved by European Medicines Agency for children aged 6 years and older. ${ }^{18}$ On the basis of such considerations, the aim of this review is to discuss the basic pharmacology and clinical use of omalizumab.

\section{Mechanism of action and basic pharmacology}

Omalizumab (molecular weight $150 \mathrm{kD}$ ) is a recombinant humanized antibody comprising a human IgG framework which embeds the complementarity-determining region obtained from an anti-IgE antibody raised in mice. ${ }^{19}$ Consequently, only about $5 \%$ of the humanized monoclonal anti-IgE antibody includes residues of murine origin, and these structural features of course minimize the risk of developing an immune response towards the nonself protein. ${ }^{20}$ Omalizumab selectively binds with high affinity to the C\&3 domain of IgE. In particular, one IgE molecule has two antigenic sites for omalizumab, and can thus be bound by two drug molecules at the same time; similarly, one omalizumab molecule has two antigen-binding loci $\left(\mathrm{V}_{\mathrm{H}}-\mathrm{V}_{\mathrm{L}}\right.$ domains of $\operatorname{IgG}$ ), and can thereby interact with two IgE molecules at the same time. ${ }^{21}$ Therefore, binding of omalizumab to free IgE results in the formation of $\mathrm{IgE} / \mathrm{anti}-\mathrm{IgE}$ complexes, which can exist as trimers (molecular weight of about $500 \mathrm{kD}$ ) or, less frequently, as examers (molecular weight about $1000 \mathrm{kD}$ ). ${ }^{22}$ The small dimensions of these biologically inert IgE/anti-IgE immune complexes contribute significantly to their safety. Indeed, IgE/omalizumab aggregates are soluble, do not bind 
complement, and do not precipitate in the kidney, thus they do not cause immune complex-related diseases. ${ }^{23}$ These IgE/ anti-IgE complexes are easily cleared from the circulation by the reticuloendothelial system, through the interaction of their IgG component with the Fc $\gamma$ receptors of the hepatic sinusoidal endothelial cells. ${ }^{22} \mathrm{IgE}$, as well as the IgG omalizumab, can freely cross capillaries, thereby distributing between the vascular and the extravascular compartments. On the contrary, the IgE/omalizumab aggregates do not diffuse through capillary walls and are also characterized by a marked stability, due to the high affinity of omalizumab for IgE. Because of these features, IgE/omalizumab immune complexes remain and accumulate where they are generated, namely in either the blood circulation or local tissues, such as the airways and nasal mucosa. ${ }^{21}$

The C 83 domain of $\operatorname{IgE}$ is the binding site shared by both FceRI and FceRII/CD23 receptors. ${ }^{24}$ The latter, expressed by B lymphocytes, monocytes, eosinophils, and epithelial cells, are structurally characterized by an extracellular trimeric $\alpha$-helical coiled-coil "stalk", three C-type lectin "head domains", and the C-terminal tails. ${ }^{10}$ The head domain interacts with the outer side of an $\mathrm{IgE} C \varepsilon 3$ domain in a $\mathrm{Ca}^{2+}$ dependent manner. ${ }^{21}$ The main consequences of FceRII/ CD23 activation include upregulation of IgE synthesis and facilitation of $\mathrm{B}$ cell-operated antigen presentation to

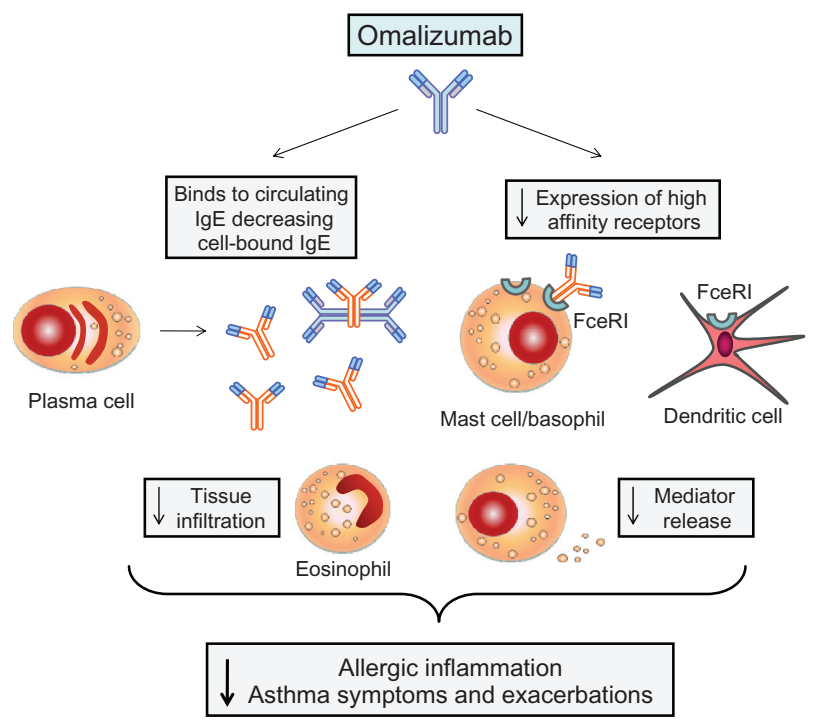

Figure I Mechanism of action of omalizumab. Omalizumab binds to $\lg E$, thus forming immune complexes that reduce levels of circulating free $\lg E$ and prevent their interactions with high-affinity lgE receptors (FcERI) expressed by dendritic cells, mast cells, basophils, and eosinophils. As a consequence, IgE-dependent antigen presentation, mast cell/basophil degranulation, and eosinophil infiltration are inhibited. Anti-lgE therapy with omalizumab also results in decreased FcERI expression. All these effects are responsible for a reduction of allergic airway inflammation, as well as of related asthma symptoms and exacerbations.
$\mathrm{T}$ lymphocytes. Therefore, the interaction of omalizumab with IgE will prevent the latter from binding to both FceRI and FceRII/CD23 expressed by several different cell types (Figure 1), thus interrupting the allergic cascade. ${ }^{21}$ This implies that omalizumab can interfere with biological functions mediated by the stimulation of both high-affinity and low-affinity IgE receptors. Blocking IgE binding to FceRI on mast cells and basophils inhibits allergen-induced degranulation, thus preventing histamine and tryptase release, and also affects lipid mediator production and cytokine/chemokine gene expression. Moreover, blocking IgE binding to FceRI receptors also reduces FceRI expression on basophils by approximately $97 \%$, which correlates with a decrease in responsiveness of basophils and mast cells to antigen challenge. ${ }^{20}$ It can thus be inferred that $\operatorname{IgE}$ is able to upregulate the synthesis of its own highaffinity receptors. Furthermore, binding of omalizumab to circulating IgE reduces free serum IgE levels by $96 \%-99 \%{ }^{25}$ Omalizumab may also be able to suppress new IgE production, probably by inhibiting IgE interactions with the FceRII/CD23 receptors expressed on IgE-switched B cells. A further mechanism contributing to the reduction of $\operatorname{IgE}$ synthesis may be secondary to an omalizumab-dependent decrease in the production of IgE-switching cytokines, such as interleukin-4 and interleukin-13. In addition to binding omalizumab, IgE molecules within the immune complexes formed by this drug can still bind allergens (at the $\mathrm{V}_{\mathrm{L}}-\mathrm{V}_{\mathrm{H}}$ domains), thereby neutralizing some of the antigenic stimuli. ${ }^{20}$ In fact, omalizumab-linked IgE antibodies cannot interact further with their receptors, thus potentially acting as protective agents against incoming allergens, which in this way will be trapped and prevented from reaching residual FceRI-bound IgE on mast cells. Furthermore, by inhibiting IgE binding to FceRI receptors expressed on dendritic cells, omalizumab can reduce the efficiency of antigen presentation to $\mathrm{T}$ lymphocytes. Omalizumab cannot bind to receptor-bound IgE and, consequently, does not mimic the IgE cross-linking induced by allergens, thus being largely nonanaphylactogenic in clinical use.

\section{Practical use and overview of clinical studies}

The dosage of omalizumab can be determined by taking into consideration serum baseline levels of total $\operatorname{IgE}$ and the patient's body weight. ${ }^{26}$ Indeed, by matching these two parameters according to the currently available dosing tables, it is possible to achieve, with regard to the omalizumab/ 
IgE ratio, the large molar excess (ranging from about 7:1 to approximately $15: 1$ ) required to optimize the efficacy of anti-IgE therapies. Utilization of omalizumab is currently approved only for allergic asthmatic patients with total plasma IgE levels ranging from 30 to 1500 (European Union) or from 30 to 700 (US) IU/mL, and dosing tables approximately reflect the use of the following formula: $0.016 \mathrm{mg} / \mathrm{kg}$ per IU/ $\mathrm{mL}$ of IgE per 4 weeks. After subcutaneous administration, omalizumab achieves a bioavailability of $62 \%$, then reaches its peak serum concentration within 7-8 days and has a half-life of 19-22 days. $^{27}$

Omalizumab binds circulating free IgE regardless of antigen specificity, thereby being potentially useful for atopic disorders caused by either perennial or seasonal allergens, as well as by multiple sensitizations. ${ }^{28}$ Unlike IgE, which has a half-life of 1-2 days in humans, omalizumab circulates similarly to human IgG1 antibodies, with a halflife of about 21 days even when it binds IgE thus forming trimeric or exameric complexes. ${ }^{29}$ Due to these pharmacokinetic properties, omalizumab is usually administered subcutaneously every 4 weeks. Shorter intervals are chosen only for practical reasons when patients require relatively high drug doses. In fact, because each vial of omalizumab contains $150 \mathrm{mg}$, in order to avoid multiple subcutaneous injections at the same time, subjects needing more than $300 \mathrm{mg}$ monthly are treated every 2 weeks. After a single subcutaneous injection, omalizumab induces an 84\%-99\% reversible reduction of unbound serum IgE, low levels of which last for 4-6 weeks. ${ }^{30}$ Clinical responses to omalizumab treatment are variable and strictly individual. Currently, an overall physician's evaluation of the effects of omalizumab is recommended after 16 weeks of therapy. ${ }^{31}$ In this regard, Bousquet et al have recently shown, basing their observations on physicians' global evaluation of treatment effectiveness, that patient responsiveness to omalizumab detected at week 16 persisted at week $32 .{ }^{32}$ However, among 71 allergic asthmatics who did not exhibit a clinical response within the first 16 weeks of treatment with omalizumab added to optimized asthma therapy, 27 responded to omalizumab after a further 16 weeks of treatment. This suggests that, by prolonging the initial observational time, it could be possible to extend the therapeutic benefits of omalizumab also to a subgroup of potential "late responders", incorrectly classified as nonresponders on the basis of a 16-week period of clinical evaluation.

The first clinical studies showed that, after 9 weeks of treatment, omalizumab was able to inhibit both early and late asthmatic responses triggered by allergen inhalation. ${ }^{33}$
Since then, several multicenter, randomized, double-blind, placebo-controlled Phase III trials have been carried out in adolescents and adults with moderate-to-severe asthma. ${ }^{34-39}$ Omalizumab has been given in addition to stable treatment with inhaled corticosteroids and other anti-asthma drugs. Taking together the results of these studies, fewer asthma exacerbations, improvements in asthma symptoms and quality of life, and decreased requirements for both inhaled corticosteroids and rescue bronchodilators were observed in patients treated with omalizumab compared with placebo. ${ }^{40-42}$ Moreover, in comparison with placebo-treated asthmatics, omalizumab-treated patients had fewer hospitalizations, unscheduled outpatient visits, and emergency room visits. Overall, patients who benefited most from omalizumab treatment were those with the poorest lung function, and receiving the highest inhaled corticosteroid doses. Therefore, omalizumab exerted its greatest effects in severe asthma, thus being particularly useful as an add-on treatment option for patients whose disease was not well controlled.

In particular, the Busse trial included patients with severe allergic asthma, whose disease exacerbations were significantly decreased by omalizumab during two study phases, including inhaled corticosteroid treatments with stable or reduced doses, respectively. ${ }^{34}$ In addition, a higher percentage of patients receiving omalizumab than those on placebo were able to reduce their inhaled corticosteroid intake. These findings were also confirmed by Solér et al and Holgate et al, who enrolled subjects with moderate-to-severe allergic asthma whose symptoms were not well controlled by regular therapy with inhaled corticosteroids. ${ }^{35,36}$ The SOLAR (Study of Omalizumab in comorbid Asthma and Rhinitis) study was designed to test the effects of omalizumab in concomitant allergic asthma and rhinitis. ${ }^{37}$ During a 28 -week treatment with omalizumab, both adolescents and adults with moderate-to-severe asthma and moderate-to-severe persistent rhinitis were investigated. Omalizumab elicited significant improvements in quality of life related to both asthma and rhinitis, assessed by the Asthma Quality-of-Life Questionnaire and Rhinitis Quality-of-Life Questionnaire. These results are very interesting because of the frequent association between asthma and rhinitis, two allergic diseases linked by reciprocal pathogenic connections.

One of the most important studies to evaluate the clinical effects of omalizumab was INNOVATE (Investigation of Omalizumab in Severe Asthma Treatment). ${ }^{39}$ This study included 419 allergic patients aged 12-75 years with severe persistent asthma, from 108 centers in 14 countries. Participating subjects had decreased lung function $\left(\mathrm{FEV}_{1}\right.$ 
$41 \%-80 \%$ predicted at randomization), associated with a recent history of clinically significant exacerbations. In particular, patients had experienced an average of 2.1 exacerbations per year, and $67 \%$ were considered to be at risk of asthma-related mortality, assessed on the basis of emergency room visits, hospitalizations, or intubations in the previous year. Symptom control was not satisfactory, despite stable inhaled therapy with relatively high doses of corticosteroids and long-acting $\beta_{2}$-agonists. In addition, an average of $31 \mathrm{school} /$ work days had been missed in the previous year. Following an 8-week run-in phase, patients were randomized in a double-blind manner to receive 28 weeks of treatment with either omalizumab or placebo as add-on treatment to 2002 Global Initiative for Asthma step 4 therapy. The results of INNOVATE show that, when compared with placebo (210 patients), omalizumab (209 patients) significantly decreased the numbers of emergency visits, as well as severe asthma exacerbations requiring unscheduled systemic corticosteroids. Omalizumab also elicited a clinically meaningful improvement in quality of life, evaluated by the Asthma Quality-of-Life Questionnaire ( $>0.5$ points). Furthermore, with respect to placebo, omalizumab produced significant improvements in both asthma symptom score and peak expiratory flow. Treatment with omalizumab was considered to be globally more effective than placebo by both the patients and the investigating physicians.

The efficacy of omalizumab in adults, adolescents, and children with moderate-to-severe asthma has been further confirmed by a recent meta-analysis of eight placebocontrolled studies in at least 3000 patients and published between 2001 and 2009. ${ }^{43}$ This systematic review considered reductions of steroid use and of asthma exacerbations as the primary outcomes; secondary outcome measures included lung function, use of rescue medication, asthma symptoms, and health-related quality of life. Two further recent placebocontrolled trials have confirmed the efficacy of omalizumab. In the first one, including 850 patients aged 12-75 years, Hanania et al showed that, when compared with placebo, 48 weeks of treatment with omalizumab significantly decreased asthma symptoms and exacerbations, as well as the mean daily number of albuterol puffs. ${ }^{44}$ Moreover, Busse et al have recently shown in 419 inner city children, adolescents, and young adults with persistent allergic, moderate-to-severe asthma, that addition of omalizumab to guideline-based therapy for 60 weeks further improved asthma control, nearly eliminated seasonal peaks in exacerbations, and also reduced the need for inhaled corticosteroids. ${ }^{45}$ Furthermore, the globally favorable pharmacodynamic pattern of omalizumab has also been corroborated by several Phase IV postmarketing surveillance trials in patients affected by severe persistent allergic asthma treated with omalizumab for 5-12 months in real-life practice in France, Germany, Belgium, and Italy. ${ }^{46-50}$

One of the most important questions related to omalizumab therapy refers to its duration, ie, how long should this treatment last? Given the unusual mechanism of action of omalizumab, a tentative answer could be "forever". Indeed, after a few months of treatment, discontinuation of omalizumab in atopic subjects resulted in a return to the pretreatment clinical state, due to a relatively rapid (within months) rise in free serum IgE levels, associated with repopulation of basophil surfaces with both IgE and FceRI receptors. ${ }^{51}$ More recently, it has also been shown that either a dose reduction of omalizumab therapy or its complete cessation leads to increases towards baseline levels of both free serum IgE concentrations and allergen-specific skin prick test reactivity, evaluated as wheal-and-flare reactions. ${ }^{52}$ Medical practice also suggests that if omalizumab treatment is interrupted for whatever reason, asthma symptoms and exacerbations relapse within a few months. However, it has been reported that 6 years of treatment with omalizumab induce durable improvement in asthma symptoms and lung function, which was maintained in 14 of 18 patients for periods of 12-14 months after drug withdrawal. ${ }^{53}$ This persistent asthma control was paralleled by a downregulation in basophil activity, still detectable 1 year after interruption of omalizumab administration. This report suggests that anti-IgE therapy can induce long-term remission of the allergic state, possibly by inhibiting IgE production and depleting IgE-committed B memory cells. ${ }^{21}$ Of course, further studies are required to verify whether omalizumab should be prescribed lifelong or as a relatively long-term course. Although the optimal duration of omalizumab treatment remains unclear, there is no doubt that the injections need to be continued for very long periods of time.

Another problem related to the use of this drug is its high cost. However, if omalizumab treatment is restricted to selected patients with severe persistent and uncontrolled allergic asthma, who respond within 16 weeks with a marked improvement in disease control, this therapy could be cost-effective. ${ }^{40}$ This inference from clinical practice has been confirmed by an analysis of the incremental cost-effectiveness ratio of adding omalizumab to standard therapy, ${ }^{54}$ based on data obtained from the real-life, 1-year randomized ETOPA trial. ${ }^{38}$ To determine the incremental cost-effectiveness ratio for omalizumab, the cost/qualityadjusted life year ratio was calculated. Canada was used 
as the reference country, and only subjects receiving high doses of inhaled corticosteroids plus long-acting $\beta_{2}$-agonists were considered. Based on these reliable criteria, the authors of this analysis concluded that "omalizumab add-on therapy in patients with severe persistent asthma results in a cost-per-QALY ratio that compares favorably with other uses of scarce healthcare resources that are recommended by national reimbursement bodies and could be considered cost-effective". ${ }^{54}$ However, this analysis referred to a small open-label study, and was limited to asthmatic subjects who were responsive to omalizumab. The results obtained from the multinational INNOVATE study appear to be more reliable, and show that the cost of omalizumab was offset by improved quality of life and had an attractive incremental cost-effectiveness ratio in patients with severe allergic asthma who remained symptomatic and had an increased risk of acute exacerbations despite best available standard care..$^{55,56}$ On the other hand, further comparative economic evaluations of the cost-effectiveness of omalizumab have confirmed that, in patients with severe persistent allergic asthma, add-on therapy is comparable with or more favorable than other biologic treatments for chronic disorders, such as rheumatoid arthritis, Crohn's disease, and multiple sclerosis. ${ }^{57}$ These considerations are consistent with the conclusions of a more recent study, the results of which suggest that, from the US payer perspective, the cost-effectiveness of omalizumab may be similar to other biologics. Moreover, cost-effectiveness improves when a 16-week assessment of response is used to guide decisions regarding long-term treatment. ${ }^{58}$ This economically advantageous utilization of omalizumab is thus linked to its sparing effect on the heavy burden of resources depleted by patients with the most severe forms of asthma.

With regard to the effects of omalizumab on lung function, inconsistent data have been reported by various clinical trials. ${ }^{40}$ Indeed, a decrease in free IgE does not necessarily affect $\mathrm{FEV}_{1}$ and $\mathrm{FEV}_{1}$ /forced vital capacity ratio. ${ }^{59}$ Therefore, the effects of omalizumab on $\mathrm{FEV}_{1}$ are quite controversial, and many studies have shown no significant change in this functional parameter. ${ }^{40}$ However, some increases in $\mathrm{FEV}_{1}$ have been occasionally recorded after several weeks of treatment with omalizumab. ${ }^{29,38}$ Furthermore, according to a recent open-label study performed in patients with severe uncontrolled allergic asthma randomized to receive best standard anti-asthma therapy with or without omalizumab, a significant increase in percentage predicted $\mathrm{FEV}_{1}$ has been observed throughout a 1-year period of anti-IgE treatment in comparison with control values. ${ }^{60}$ Moreover, there may be an association between the reduction in exacerbation frequency elicited by omalizumab and the recorded improvement of airflow limitation. This observation is consistent with the reported relationship between recurrence of asthma exacerbations and deterioration of lung function. ${ }^{61}$ In particular, the exacerbation-prone phenotype of asthma may be characterized by a vicious pathophysiologic circuit sustained by exacerbation-driven inflammation leading to bronchial narrowing, which in turn predisposes to repetitive exacerbation cycles. This self-perpetuating airway injury can thus be interrupted by omalizumab. Controversial findings have also been reported with regard to the effects of omalizumab on bronchial hyper-responsiveness. In particular, omalizumab does not seem to affect the airway response to methacholine. ${ }^{62,63}$ However, bronchoconstrictive effectors that act directly on airway smooth muscle are not the most suitable stimuli for testing the effects of omalizumab on bronchial hyper-responsiveness. Indeed, after 4 weeks of treatment, omalizumab significantly attenuated the airway response to inhaled adenosine 5'monophosphate (AMP) in subjects with mild-to-moderate allergic asthma. ${ }^{63}$ AMP-induced bronchoconstriction is due to stimulation of adenosine $\mathrm{A}_{2 \mathrm{~B}}$ receptors located on mast cells, so the bronchoprotection against AMP afforded by omalizumab is probably dependent on its ability to inhibit mast cell activation synergistically triggered by allergens and other degranulating agents like AMP.

Very interesting also are the effects of omalizumab on various markers of airway inflammation. During the steroid reduction phase of a pediatric study carried out in allergic asthmatic children, when compared with placebo, omalizumab was able to maintain the fractional concentration of exhaled nitric oxide (a reliable noninvasive biomarker of bronchial inflammation) at significantly lower levels. ${ }^{64}$ These findings have also been recently confirmed by another study which demonstrated that, compared with placebo, omalizumab reduced fractional concentration of exhaled nitric oxide levels during an observation period of 48 weeks. ${ }^{44}$ Moreover, omalizumab was also shown to be capable of decreasing eosinophil numbers in peripheral blood, ${ }^{65}$ as well as in induced sputum and bronchial biopsies. ${ }^{62}$ This effect of omalizumab is likely due to the induction of apoptosis in eosinophils. In fact, omalizumab can increase the numbers of eosinophils stained by the apoptotic marker annexin $\mathrm{V}$, and this effect is paralleled by an omalizumabdependent decreased synthesis of eosinophil survival factors, such as granulocyte-macrophage colony-stimulating factor. ${ }^{66}$ 
In particular, peripheral blood eosinophils are currently believed to be reliable inflammatory biomarkers, and useful for monitoring the anti-inflammatory effects of omalizumab. In this regard, it is remarkable that a recent pooled analysis of data from several trials and involving patients with moderate-to-severe persistent allergic asthma treated with omalizumab, has found some degree of correlation between an omalizumab-induced decrease in peripheral blood eosinophils and various clinical and functional outcomes; the latter included a reduced requirement for management of exacerbations with oral steroid bursts, an increased $\mathrm{FEV}_{1}$, and a positive global evaluation of treatment effectiveness by the investigators. ${ }^{67}$

\section{Safety}

Overall, omalizumab is well-tolerated, and the most frequent adverse events are local injection site reactions, usually manifesting as warmth, erythema, swelling, bruising, and occasional urticaria-like eruptions. Other relatively frequent adverse effects include headache, fatigue, and nausea. The pivotal Phase III clinical trials have shown that the frequencies of adverse events were similar between the omalizumab and control groups; the majority of unwanted side effects were of short duration and mildly to moderately severe. ${ }^{68}$ This side effect profile has been confirmed by real-life studies which have made it possible to monitor omalizumab-treated patients for up to 3 years. ${ }^{46}$

Although omalizumab is considered to be a nonanaphylactogenic antibody, anaphylactic and anaphylactoid reactions have been sporadically reported. Indeed, IgE- or IgG-mediated hypersensitivity reactions against the small murine portion of the omalizumab molecule can occur. Moreover, although the excipients (sucrose, L-histidine hydrochloride monohydrate, L-histidine, polysorbate 20) present in omalizumab preparations are generally considered to be safe, remote reactions to these components can occur. ${ }^{69}$ In particular, both in vitro and in vivo immunologic evaluations of two patients who experienced anaphylaxis after 1 year of omalizumab treatment concluded that the likely cause was the excipient polysorbate. ${ }^{70}$ In order to address these problems, the Omalizumab Joint Task Force was formed at the 2007 annual meeting of the American Academy of Allergy, Asthma and Immunology, to review the data on anaphylaxis and anaphylactoid reactions reported by Phase III clinical trials and postmarketing surveillance studies. Omalizumab Joint Task Force members inferred that, among 39,510 patients receiving omalizumab between
June 1, 2003 and December 31, 2005, 35 manifested 41 episodes of anaphylaxis associated with omalizumab, corresponding to an anaphylaxis reporting rate of $0.09 \%{ }^{69}$ These episodes included increased asthma symptoms and urticaria, shortness of breath, tongue swelling, watery itchy eyes, and subjective sensations of throat closing. All patients responded to anti-anaphylactic treatment, and there were no fatalities or respiratory failures requiring intubation. Among the 41 reported anaphylactic events, timing information was available for only 36 episodes. Considering the latter, $22(61 \%)$ reactions occurred in the first 2 hours after one of the first three doses, whereas five of the episodes occurring after the fourth or later doses took place within 30 minutes. Therefore, an observation period of 2 hours for the first three injections, and of 30 minutes for the following doses would have made it possible to detect $75 \%$ of these anaphylactic reactions. Moreover, advising patients to be equipped with an epinephrine autoinjector will probably allow management of anaphylactic events occurring outside the recommended observation period. ${ }^{69}$

Given the role played by IgE in immune defense against parasitic infestation, the risk of developing such infections could be associated with the use of anti-IgE therapies. However, evolutionary theories suggest that although $\operatorname{IgE}$ is very important in protecting animals and even humans living in primitive habitats, these antibodies seem to have become nonessential in many regions of the world characterized by relatively clean household and community environments. On the other hand, according to the results of a study carried out in allergic subjects resident in poor urban areas of Brazil and at high risk of helminthic infections, omalizumab appeared to be effective and safe, although its use was associated with a slightly increased risk of parasitic infections. ${ }^{71}$ Therefore, caution should be recommended in the use of omalizumab by patients at high risk of helminthic infections, particularly when living in or travelling to areas where these infections are endemic. In the event of unsatisfactory responses to conventional antihelminthic treatments, discontinuation of omalizumab should be considered.

A major concern arises from the small increase in the numbers of malignancies, including tumors of the breast, prostate, and parotid gland, as well as a case of lymphoma detected in initial studies of omalizumab-treated patients compared with control groups. ${ }^{30}$ However, no difference in cancer incidence was found between subjects undergoing omalizumab therapy and the general population. Furthermore, most cancers occurred within 1 year from the beginning of omalizumab 
therapy, thus suggesting that they were likely pre-existing, because drug-induced malignancies usually develop after longer exposures. Therefore, on the basis of these considerations, also including the diversity in the types of neoplasms observed, panels of blinded and independent oncologists concluded that no causal relationship between omalizumab administration and cancer development can be hypothesized.

Some sporadic cases of Churg-Strauss syndrome possibly related to omalizumab treatment have been reported. ${ }^{72-74}$ Similar to previous observations regarding the use of leukotriene receptor antagonists, ${ }^{75}$ it is not yet clear whether these drugs, including omalizumab, may cause ChurgStrauss syndrome, or simply unmask pre-existing latent disease because they facilitate corticosteroid tapering and withdrawal. However, at least one report refers to a patient who had only received two short courses of oral corticosteroids in the year before omalizumab administration was initiated. ${ }^{73}$ This patient experienced a paradoxical increase in blood eosinophil count during treatment with omalizumab, even though this drug is a potential inducer of eosinophil apoptosis. Further pharmacovigilance studies are of course needed to ascertain if the development of Churg-Strauss syndrome can be induced by omalizumab. Caution is recommended when considering use of omalizumab in patients affected by this relatively rare vasculitis.

More recently, some concerns have been raised by the US Food and Drug Administration about the potential occurrence of cardiovascular and cerebrovascular side effects in patients treated with omalizumab, when compared with subjects not receiving this drug. ${ }^{76}$ However, the Food and Drug Administration is not recommending any changes to the prescribing information for omalizumab, and is not advising patients to stop taking this drug. In particular, because it has been hypothesized that omalizumab could induce an increase in ischemic heart disease, arrhythmias, cardiac failure, pulmonary hypertension, and thrombotic events, an ongoing observational study (EXCELS, Evaluating Clinical Effectiveness and Long-Term Safety in Patients With Moderate to Severe Asthma) is evaluating the long-term safety profile of omalizumab in patients followed for 5 years. However, a recent systematic analysis of eight placebo-controlled trials in 3429 participants has not detected increased cardiovascular risk due to the use of omalizumab. ${ }^{43}$ On the contrary, four cases of adverse cardiovascular effects, including angina pectoris, tachyarrhythmia, and atrial fibrillation were reported in the placebo groups. Moreover, a case of cardiac arrest also occurred in the placebo group.
Preliminary studies including small numbers of women who have received omalizumab during pregnancy have not detected any significant difference in comparison with control groups with regard to normal deliveries and spontaneous abortion rates. ${ }^{77}$

Therefore, the current consensus among clinicians is that the use of omalizumab is safe. However, as with any relatively new class of drugs, continued surveillance is needed as its utilization in real life practice continues to grow, thus involving progressively increasing numbers of patients. $^{78}$

\section{Future perspectives}

Although omalizumab is very effective in reducing allergic bronchial inflammation, its potential effects on airway remodeling, which is a key feature of severe asthma, are still not well understood. ${ }^{79}$ However, it is noteworthy that high-affinity IgE receptors are also expressed on the surface of structural airway cells, such as bronchial epithelial cells. The latter are indeed actively involved in the production of growth factors playing a central role in remodeling events in the airways of patients with asthma, ${ }^{80}$ especially those with the most severe disease phenotypes. Therefore, omalizumab could potentially interfere with the synthetic activity of bronchial epithelium, which contributes remarkably to the airway remodeling process. In this regard, it has been reported that omalizumab was able to decrease significantly the production of transforming growth factor beta by bronchial epithelial cells cultured in a medium containing atopic serum from a dust mite-sensitive patient and exposed to the stimulatory actions of interleukin- $1 \beta$ or ragweed allergen. ${ }^{81}$ Omalizumab could thus inhibit the fibrotic effects exerted by transforming growth factor beta in asthmatic airways via this mechanism. Furthermore, it has recently been reported that omalizumab can significantly decrease the concentration of endothelin-1 in the exhaled breath condensate of patients with severe persistent allergic asthma. ${ }^{82}$ Endothelin-1 is a peptide mediator produced by vascular endothelial cells, bronchial epithelial cells, and mast cells, and is actively involved in the pathogenesis of airway structural changes, such as subepithelial fibrosis and proliferation of bronchial smooth muscle cells. On the other hand, in experimental murine models of allergic asthma, omalizumab has been shown to reduce airway wall thickness, mucous gland metaplasia, and subepithelial fibrosis. On the basis of these findings, an ongoing study (EXPLORE) is investigating if omalizumab may be effective in preventing airway structural changes in asthmatic patients, in bronchial biopsies performed at different time points over 78 weeks. 


\section{Conclusion}

Availability of omalizumab in medical practice represents a remarkable advance in the management of severe persistent allergic asthma. Omalizumab makes it possible to improve disease control in many atopic patients who, although receiving optimized standard therapy, still experience a persistence of respiratory symptoms and a high frequency of asthma exacerbations. The efficacy of omalizumab in reducing allergic airway inflammation and its clinical manifestations have been demonstrated in several trials, including real-life investigations. With the exception of a few sporadically reported relevant side effects, the drug appears to be safe. However, future investigations are needed in order to evaluate further the long-term actions of omalizumab. Moreover, given the wide expression of IgE receptors on cross-talking immune/inflammatory and airway resident cells, it will be very interesting to explore whether anti-IgE therapy may eventually prevent and/or attenuate the development of immune-mediated airway remodeling and progressive functional decline, thus possibly affecting the natural history of severe asthma.

\section{Disclosure}

The authors report no conflicts of interest in this work.

\section{References}

1. Holgate ST, Arshad HS, Roberts GC, Howarth PH, Thurner P, Davies DE. A new look at the pathogenesis of asthma. Clin Sci. 2010; 118(7):439-450.

2. Anderson GP. Endotyping asthma: new insights into key pathogenetic mechanisms in a complex, heterogeneous disease. Lancet. 2008; 372(9643):1107-1119.

3. Anandan C, Nurmatov U, van Schayck OCP, Skeih A. Is the prevalence of asthma declining? Systematic review of epidemiological studies. Allergy. 2010;65(2):152-167.

4. Masoli M, Fabian D, Holt S, Beasley R. The global burden of asthma: executive summary of the GINA dissemination committee report. Allergy. 2004;59(5):469-478.

5. Bateman ED, Boushey HA, Bousquet J, et al. Can guideline-defined asthma control be achieved? The Gaining Optimal Asthma ControL (GOAL) study. Am J Respir Crit Care Med. 2004;170(8):836-844.

6. Fanta CH. Drug therapy: asthma. N Engl J Med. 2009;360(10): 1002-1014.

7. Boulet LP. Influence of comorbid conditions on asthma. Eur Respir J. 2009;33(4):897-906.

8. Dolan CM, Fraher KE, Bleecker ER, et al. Design of baseline characteristics of the epidemiology and natural history of asthma: outcomes and treatment regimens (TENOR) study: a large cohort of patients with severe or difficult-to-treat asthma. Ann Allergy Asthma Immunol. 2004;92(1):32-39.

9. Galli SJ, Tsai M, Piliponsky AM. The development of allergic inflammation. Nature. 2008;454(7203):445-454.

10. Gould HJ, Sutton BJ. IgE in allergy and asthma today. Nat Rev Immunol. 2008;8(3):205-217.

11. Pelaia G, Vatrella A, Calabrese C, Mazzarella G, Marsico SA. New perspectives in asthma treatment. Allergy. 2000;55(Suppl 61): $60-66$.
12. Tarantini F, Baiardini I, Passalacqua G, Braido F, Canonica GW. Asthma treatment: 'Magic bullets which seek their own targets'. Allergy. 2007; 62(6):605-610.

13. Holgate ST, Polosa R. Treatment strategies for allergy and asthma. Nat Rev Immunol. 2008;8(3):218-230.

14. Hanania NA. Targeting airway inflammation in asthma: current and future therapies. Chest. 2008;133(4):989-998.

15. ENFUMOSA (European Network For Understanding Mechanisms Of Severe Asthma) Study Group. The ENFUMOSA cross-sectional European multicentre study of the clinical phenotype of chronic severe asthma. Eur Respir J. 2003;22(3):470-477.

16. Haselkorn T, Borish L, Miller DP, Weiss ST, Wong DA. High prevalence of skin test positivity in severe or difficult-to-treat asthma. J Asthma. 2006;43(10):745-752.

17. Global Initiative for Asthma (GINA). Global strategy for asthma management and prevention. Available at: http://www.ginasthma.org. Accessed April 18, 2011.

18. European Public Assessment Report (Xolair). Available at: http:// www.ema.europa.eu/humandocs/PDFs/EPAR/Xolair/emea-combinedh606en.pdf. Accessed April 18, 2011.

19. Presta LG, Lahr SJ, Shields RL, et al. Humanization of an antibody directed against IgE. J Immunol. 1993;151(5):2623-2632.

20. Spector S. Omalizumab efficacy in allergic disease. Panminerva Med. 2004;46(2):141-148.

21. Chang TW, Wu PC, Hsu CL, Hung AF. Anti-IgE antibodies for the treatment of IgE-mediated allergic diseases. Adv Immunol. 2007; 93:63-119.

22. Hochhaus G, Brookman L, Fox H, et al. Pharmacodynamics of omalizumab: implications for optimised dosing strategy and clinical efficacy in the treatment of allergic asthma. Curr Med Res Opin. 2003; 19(6):491-498.

23. Fox JA, Hotaling TE, Struble C, Ruppel J, Bates DJ, Schoenhoff MB. Tissue distribution and complex generation with $\operatorname{IgE}$ of an anti- $\operatorname{IgE}$ antibody after intravenous administration in cynomolgus monkeys. J Pharmacol Exp Ther. 1996;279(2):1000-1008.

24. Presta L, Shields R, O'Connell L, et al. The binding site of a human immunoglobulin E for its high affinity receptor. J Biol Chem. 1994; 269(42):26368-26373.

25. Holgate S, Casale T, Wenzel S, Bousquet J, Deniz Y, Reisner C. The antiinflammatory effects of omalizumab confirm the central role of $\mathrm{IgE}$ in allergic inflammation. J Allergy Clin Immunol. 2005;115(3): 459-465.

26. Marcus P. Incorporating anti-IgE (omalizumab) therapy in clinical practice: practice management implications. Chest. 2006;129(2): 466-474.

27. Hendeles L, Sorkness CA. Anti-immunoglobulin E therapy with omalizumab for asthma. Ann Pharmacother. 2007;41(9): 1397-1410.

28. D'Amato G. Role of anti-IgE monoclonal antibody (omalizumab) in the treatment of bronchial asthma and allergic respiratory diseases. Eur J Pharmacol. 2006;533(1-3):302-307.

29. Lanier BQ, Corren J, Lumry W, Liu J, Fowler-Taylor A, Gupta N. Omalizumab is effective in the long-term control of severe allergic asthma. Ann Allergy Asthma Immunol. 2003;91(2):154-159.

30. Miller CWT, Krishnaswamy N, Johnston C, Krishnaswamy G. Severe asthma and the omalizumab option. Clin Mol Allergy. 2008;6:4.

31. Bousquet J, Rabe K, Humbert M, et al. Predicting and evaluating response to omalizumab in patients with severe allergic asthma. Respir Med. 2007;101(7):1483-1492.

32. Bousquet J, Siergiejko Z, Swiebocka E, et al. Persistency of response to omalizumab therapy in severe allergic (IgE-mediated) asthma. Allergy. 2011;66(5):671-678.

33. Fahy JV, Fleming HE, Wong HH, et al. The effect of an anti-IgE monoclonal antibody on the early- and late-phase responses to allergen inhalation in asthmatic subjects. Am J Respir Crit Care Med. 1997; 155(6):1828-1834.

34. Busse W, Corren J, Lanier BQ, et al. Omalizumab, anti-IgE recombinant humanized monoclonal antibody for the treatment of severe allergic asthma. J Allergy Clin Immunol. 2001;108(2):184-190. 
35. Solér M, Matz J, Townley R, et al. The anti-IgE antibody omalizumab reduces exacerbations and steroid requirement in allergic asthmatics. Eur Respir J. 2001;18(2):254-261.

36. Holgate ST, Chuchalin AG, Hebert J, et al. Efficacy and tolerability of a recombinant anti-immunoglobulin E antibody (omalizumab) in severe allergic asthma. Clin Exp Allergy. 2004;34(4):632-638.

37. Vignola AM, Humbert M, Bousquet J, et al. Efficacy and tolerability of anti-immunoglobulin E therapy with omalizumab in patients with concomitant allergic asthma and persistent allergic rhinitis: SOLAR. Allergy. 2004;59(7):709-717.

38. Ayres JG, Higgins B, Chilvers ER, Ayre G, Blogg M, Fox H. Efficacy and tolerability of anti-immunoglobulin E therapy with omalizumab in patients with poorly controlled (moderate-to-severe) allergic asthma. Allergy. 2004;59(7):701-708.

39. Humbert M, Beasley R, Ayres J, et al. Benefits of omalizumab as add-on therapy in patients with severe persistent asthma who are inadequately controlled despite best available therapy (GINA 2002 step 4 treatment): INNOVATE. Allergy. 2005;60(3):309-316.

40. Price D. The use of omalizumab in asthma. Prim Care Respir J. 2008; 17(2):62-72.

41. Pelaia G, Renda T, Romeo P, Busceti MT, Maselli R. Omalizumab in the treatment of severe asthma: efficacy and current problems. Ther Adv Respir Res. 2008;2(6):409-421.

42. D'Amato G, Perticone M, Bucchioni E, Salzillo A, D'Amato M, Liccardi G. Treating moderate-to-severe allergic asthma with anti-IgE monoclonal antibody (omalizumab). An update. Eur Ann Allergy Clin Immunol. 2010;42(4):135-140.

43. Rodrigo GJ, Neffen H, Castro-Rodriguez JA. Efficacy and safety of subcutaneous omalizumab vs placebo as add-on therapy to corticosteroids for children and adults with asthma: a systematic review. Chest. 2011;139(1):28-35.

44. Hanania NA, Alpan O, Hamilos DL, et al. Omalizumab in severe allegic asthma inadequately controlled with standard therapy: a randomized trial. Ann Intern Med. 2011;154(9):573-582.

45. Busse WW, Morgan WJ, Gergen PJ, et al. Randomized trial of omalizumab (anti-IgE) for asthma in inner-city children. NEngl J Med. 2011;364(11):1005-1015.

46. Molimard M, de Blay F, Didier A, Le Gros V. Effectiveness of omalizumab (Xolair) in the first patients treated in real-life practice in France. Respir Med. 2008;102(1):71-76.

47. Korn S, Thielen A, Seyfried S, Taube C, Kornmann O, Buhl R. Omalizumab in patients with severe persistent allergic asthma in a real-life setting in Germany. Respir Med. 2009;103(11): 1725-1731.

48. Brusselle G, Michils A, Louis R, et al. "Real-life" effectiveness of omalizumab in patients with severe persistent allergic asthma: the PERSIST study. Respir Med. 2009;103(11):1633-1642.

49. Cazzola M, Camiciottoli G, Bonavia M, et al. Italian real-life experience of omalizumab. Respir Med. 2010;104(10):1410-1416.

50. Molimard M, Buhl R, Niven R, et al. Omalizumab reduces oral corticosteroid use in patients with severe allergic asthma: real-life data. Respir Med. 2010;104(9):1381-1385.

51. Saini SS, MacGlashan DW, Sterbinsky SA, et al. Down-regulation of human basophil IgE and FceRI $\alpha$ surface densities and mediator release by anti-IgE infusions is reversible in vitro and in vivo. J Immunol. 1999; 162(9):5624-5639.

52. Corren J, Shapiro G, Reimann J, et al. Allergen skin tests and free IgE levels during reduction and cessation of omalizumab therapy. JAllergy Clin Immunol. 2008;121(2):506-511.

53. Nopp A, Johansson SGO, Ankerst J, Palmqvist M, Oman, H. CD-sens and clinical changes during withdrawal of Xolair after 6 years of treatment. Allergy. 2007;62(10):1175-1181.

54. Brown R, Turk F, Dale P, Bousquet J. Cost-effectiveness of omalizumab in patients with severe persistent allergic asthma. Allergy. 2007;62(2): 149-153.
55. Dewilde S, Turk F, Tambour M, Sandstrom T. The economic value of anti-IgE in severe persistent, IgE-mediated (allergic) asthma patients: adaptation of INNOVATE to Sweden. Curr Med Res Opin. 2006;22(9): 1765-1776.

56. Bahadori K, Quon BS, Doyle-Waters MM, Marra C, Fitzgerald JM. A systematic review of economic evaluations of therapy in asthma. J Asthma Allergy. 2010;3:33-42.

57. Sullivan SD, Turk F. An evaluation of the cost-effectiveness of omalizumab for the treatment of severe allergic asthma. Allergy. 2008; 63(6):670-684.

58. Campbell JD, Spackman DE, Sullivan SD. The costs and consequences of omalizumab in uncontrolled asthma from a USA payer perspective. Allergy. 2010;65(9):1141-1148.

59. Ledford DK. Omalizumab: overview of pharmacology and efficacy in asthma. Expert Opin Biol Ther. 2009;9(7):933-943.

60. Holgate S, Smith N, Massanari M, Jimenez P. Effects of omalizumab on markers of inflammation in patients with allergic asthma. Allergy. 2009;64(12):1728-1736.

61. Bai TR, Vonk JM, Postma DS, Boezen HM. Severe exacerbations predict excess lung function decline in asthma. Eur Respir J. 2007;30(3): $452-456$.

62. Djukanovic R, Wilson SJ, Kraft M, et al. Effects of treatment with antiimmunoglobulin E antibody omalizumab on airway inflammation in allergic asthma. Am J Respir Crit Care Med. 2004;170(6):583-593.

63. Prieto L, Gutiérrez V, Colas C, et al. Effect of omalizumab on adenosine 5 '-monophosphate responsiveness in subjects with allergic asthma. Int Arch Allergy Immunol. 2006;139(2):122-131.

64. Silkoff PE, Romero FA, Gupta N, Townley RG, Milgrom H. Exhaled nitric oxide in children with asthma receiving Xolair (omalizumab), a monoclonal anti-immunoglobulin E antibody. Pediatrics. 2004;113(4): e308-e312.

65. Noga O, Hanf G, Kunkel G. Immunological and clinical changes in allergic asthmatics following treatment with omalizumab. Int Arch Allergy Immunol. 2003;131(1):46-52.

66. Noga O, Hanf G, Brachmann I, et al. Effect of omalizumab treatment on peripheral eosinophil and T-lymphocyte function in patients with allergic asthma. J Allergy Clin Immunol. 2006;117(6):1493-1499.

67. Massanari M, Holgate ST, Busse WW, Jimenez P, Kianifard F, Zeldin R. Effect of omalizumab on peripheral blood eosinophilia in allergic asthma. Respir Med. 2010;104(2):188-196.

68. Holgate ST, Djukanovic R, Casale T, Bousquet J. Anti-immunoglobulin E treatment with omalizumab in allergic diseases: an update on antiinflammatory activity and clinical efficacy. Clin Exp Allergy. 2005; 35(4):408-416

69. Cox L, Platts-Mills TAE, Finegold, I, Schwartz LB, Simons FER, Wallace DV. American Academy of Allergy, Asthma and Immunology/ American College of Allergy, Asthma and Immunology Joint Task Force report on omalizumab-associated anaphylaxis. J Allergy Clin Immunol. 2007;120(6):1373-1377.

70. Price KS, Hamilton RG. Anaphylactoid reactions in two patients after omalizumab administration after successful long-term therapy. Allergy Asthma Proc. 2007;28(3):313-319.

71. Cruz AA, Lima F, Sarinho E, et al. Safety of anti-immunoglobulin E therapy with omalizumab in allergic patients at risk of geohelminth infections. Clin Exp Allergy. 2007;37(2):197-207.

72. Winchester DE, Jacob A, Murphy T. Omalizumab for asthma. $N$ Engl J Med. 2006;355(12):1281-1282.

73. Puéchal X, Rivereau P, Vinchon F. Churg-Strauss syndrome associated with omalizumab. Eur J Intern Med. 2008;19(5):364-366.

74. Bargagli E, Madioni C, Olivieri C, Penza F, Rottoli P. Churg-Strauss vasculitis in a patient treated with omalizumab. J Asthma. 2008;45(2): 115-116.

75. McDanel DL, Muller BA. The linkage between Churg-Strauss syndrome and leukotriene receptor antagonists: fact or fiction? Ther Clin Risk Manag. 2005;1(2):125-140. 
76. US Food and Drug Administration. Early communication about an ongoing safety review of omalizumab (marketed as Xolair). June 16, 2009.

77. Corren J, Casale TB, Lanier B, Buhl R, Holgate S, Jimenez P. Safety and tolerability of omalizumab. Clin Exp Allergy. 2009;39(6):788-797.

78. Tan RA, Corren J. Safety of omalizumab in asthma. Expert Opin Drug Saf. 2011;10(3):463-471.

79. Girodet PO, Ozier A, Bara I, Tunon de Lara JM, Marthan R, Berger P. Airway remodeling in asthma: new mechanisms and potential for pharmacological intervention. Pharmacol Ther. 2011;130(3): 325-337.
80. Murdoch JR, Lloyd CM. Chronic inflammation in asthma. Mutat Res. 2010;690(1-2):24-39.

81. Huang YC, Leyko B, Frier M. Effects of omalizumab and budesonide on markers of inflammation in human bronchial epithelial cells. Ann Allergy Asthma Immunol. 2005;95(5):443-451.

82. Zietkowski Z, Skiepko R, Tomasiak-Lozowska MM, BodzentaLukaszyk A. Anti-IgE therapy with omalizumab decreases endothelin-1 in exhaled breath condensate of patients with severe persistent allergic asthma. Respiration. 2010;80(6):534-542.

\section{Publish your work in this journal}

The Journal of Asthma and Allergy is an international, peer-reviewed open-access journal publishing original research, reports, editorials and commentaries on the following topics: Asthma; Pulmonary physiology; Asthma related clinical health; Clinical immunology and the immunological basis of disease; Pharmacological interventions and

\section{Dovepress}

new therapies. Issues of patient safety and quality of care will also be considered. The manuscript management system is completely online and includes a very quick and fair peer-review system, which is all easy to use. Visit http://www.dovepress.com/testimonials.php to read real quotes from published authors.

Submit your manuscript here: http://www.dovepress.com/journal-of-asthma-and-allergy-journal 